\title{
Impact of Supervisors' Perceived Communication Style on Subordinate's Psychological Capital and Cyberloafing
}

\author{
Upasnaa Agarwal \\ National Institute of Industrial Engineering \\ upasnaaagarwal@gmail.com
}

\section{Abstract}

Drawing from Conservation of Resources Theory (COR), the purpose of this paper is to examine the impact of supervisor's perceived communication style (passive, aggressive, and assertive styles) on subordinates PsyCap and cyberloafing. The study also tests the mediating role of Psychological Capital (PsyCap) in the relationship between perceived communication style (CS) of supervisor and cyberloafing. In total, 680 full-time managerial employees from seven diverse firms in India were studied through questionnaire survey. Standard instruments were used to assess the constructs. Results revealed that perceived CS of supervisors-assertive, aggressive and passive styles have an impact on cyberloafing. PsyCap partially mediated the relationship between supervisors perceived assertive and aggressive perceived CS and cyberloafing. Theoretical contributions and managerial implications of the study are discussed.

Keywords: Cyberloafing, Communication Styles, Passive, Aggressive, Assertive and PsyCap

\section{Introduction}

Internet usage has changed drastically in the past decade with the introduction of personal electronic devices like the iPhone, iPad, Android, and others (de Vass, Shee, \& Miah, 2018). It has become an embracing aspect of today's working life and is known to enhance organizational and personal productivity. Yet technology is considered as a doubled-edged sword and has its dark side too. One of the most acknowledged internet misuses, is cyberloafing, which refers any 'voluntary act of employees' using their companies' internet access during office hours to surf non-job-related web sites for personal purposes and to check (including receiving and sending) personal e-mail' (Lim, 2002, p. 677). Cyberloafing has been conceptualized as form of workplace deviance behaviour, which is voluntary in nature and violates organizational norms and threatens the well-being of the organization and/or its members (Lim, 2002; Mercado et al., 2017). It has been found to have a significant cost to employers and has negative ramifications for employees (Mercado et al., 2017). Despite its crippling effects worldwide, extant literature remains largely atheoretical and provides little insights into its precursors and underlying mechanisms (Akbulut, Dönmez, \& Dursun, 2017; Betts, Setterstrom, Pearson, \& Totty, 2018).

An impressive body of research suggests that the quality of relationship with immediate supervisor has an impact on workplace deviance behaviours (Mayer, Kuenzi, Greenbaum, Bardes, \& Salvador, 2009; Penney \& Spector, 2005). While studies provide important insights into the impact of supervisor behaviours on subordinate's work outcomes, they are limited to examining the impact of subordinate-supervisor relationship from the lens of broad theories of leadership such as transformational, ethical and authentic leadership (Liu, Chang, $\mathrm{Fu}$, Wang, \& Wang, 2012). Scholars in recent years have urged that more than the general aspects of leaders and their styles, day-to-day social interactions between supervisors and 
subordinates focusing on how employees are treated through the communication processes needs to be examined (Fairhurst \& Connaughton, 2014; De Vries, Bakker-Pieper, \& Oostenveld, 2010). Communication between a subordinate and her/his superior is at the heart of leadership influence and is believed to have tremendous implications for the survival and growth of the organization (Morrison, 2011).

Echoing this sentiment Yukl \& Mahsud (2010, p.451) said '(since) leadership in essence is a group of behaviours that are communicative in nature, it is important to examine the influence of perceived supervisor's communication style (CS) on subordinate behaviours'.

Anchored in conservation of resources theory (COR) (Hobfoll, 1989), this study tests links between three different communication styles of supervisors using Heffner's (1997) classification - passive, aggressive as well as assertive communication styles on cyberloafing. According to COR theory, employees are motivated to obtain, maintain, and invest appropriate resources to accomplish their tasks and accumulate resources generating "positive gain spirals" and avoid potential future depletion creating "negative loss spirals" (Hobfoll, 1989). We posit that supervisors perceived communication style(s) can be viewed as organizational resource which can serve to either reduce work stress and replenish their resource pool or drain existing resources (Hobfoll, 1989). The concept of psychological capital or simply PsyCap has been espoused by scholars of positive organizational behaviour (Avey, Luthans, Smith, \& Palmer, 2010; Luthans, Avolio, Avey, \& Norman, 2007). PsyCap is a personal resource, constituting of hope, efficacy, resilience, and optimism and an increasing body of research has as examined PsyCap as the explanatory mechanism in the relationship between resources and employee outcomes. However, efforts to examine the links between perceived CS of supervisor and employees PsyCap are missing. Commensurate to the COR perspective, this paper posits that perceived CS of supervisor may add to or drain subordinate's personal resources which in turn will influence their cyberloafing behaviours.

This research makes three incremental contributions to extant literature. Research on cyberloafing is primarily anecdotal and descriptive (Akbulut et al., 2017). By examining the relationship between perceived CS of supervisor (assertive, aggressive and passive) and cyberloafing, the study provides a nuanced understanding of the impact of contextual and personal resources on cyberloafing. The focus on the communication dynamics between supervisors and employees addresses a persistent gap in our understanding of leader effectiveness by modelling leadership influence as a social interaction process as it happens in real time through communication. By examining PsyCap as an underlying mechanism in CScyberloafing relationship, the study additionally addresses the question of why employee perceptions of supervisor CS affects their behaviour. Finally, this work contributes to the larger communication, PsyCap and cyberloafing literatures by examining how supervisor treatment relate to personal resources and cyberloafing outside of the US. Recent calls for cross-national work in the human interface in the information systems and management field underscore the need for additional research that expands our understanding of phenomena beyond Anglo-Saxon nations.

From a practical standpoint, managers can use this information to design organizational interventions aimed at managing cyberloafing, such as supervisors training, socialization procedures, and changes in organizational policies. 


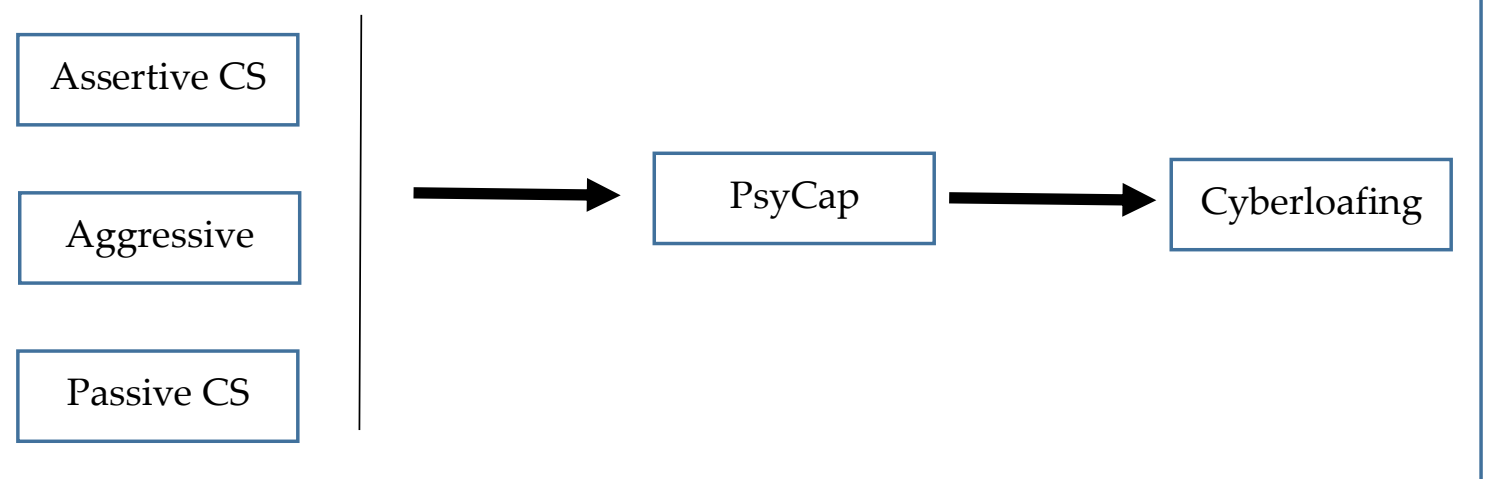

Figure 1. Conceptual Model

\section{Theory}

The Conservation of Resources (COR) theory (Hobfoll, 1989) is arguably one of the most influential theories explaining human stress and well-being and offers a useful theoretical foundation for understanding the impact of communication styles of supervisors on subordinate attitudes and behaviours. The central proposition of COR theory is that people strive to obtain, retain, and protect resources. Resources are defined as objects, personal characteristics, conditions (e.g., supervisory support), or energies (e.g., time, physical/mental energy). Two basic processes describe how resources can be lost or gained. The first process, the "resource gain" process describes that initial resources can help generate more resources that accumulate over time, ultimately creating a "gain spiral" of resources (Hakanen, Bakker, \& Jokisaari, 2011; Hobfoll, 1989, 2002). In contrast, process of "resource loss" describes that stress occurs when there is loss of resources or a threat of loss of resources. When no action is taken, this can ultimately result in a "loss spiral" in which more and more resources are lost. The theory suggests that resource losses are the driver of reactions and in the phase of resources loss, the prime human motivation is directed towards the protection and conservation of resources (Hobfoll, 1989; Halbesleben \& Bowler, 2007).

People seek to invest their resources to tackle stressful conditions and avoid negative situations, to prevent themselves from potential resource loss, and to gather additional resources. COR theory further suggests that initial resource loss makes employees vulnerable to further resource loss especially when negative emotional sequel occurs and when there is less availability of potential supportive resources (Wheeler et al., 2010).

\subsection{Cyberloafing}

Lim (2002) originally conceptualized cyberloafing as employees' use of their organizations' internet or, more simply, the "IT way of idling on the job" (p. 678). However, since cyberloafing was introduced in the academic literature, opportunities to engage in technologicallyfacilitated loafing have expanded greatly, resulting in a proliferation of conceptualizations of the construct. Recent empirical work in this area has also broadened the construct definition to include additional devices that employees can utilize to cyberloaf (e.g. tablets, smartphones), no longer requiring that technology be organizationally provided. These conceptual shifts reflect technological advances that have occurred in the past two decades.

The concept of cyberloafing has been considered and researched as a form of workplace deviance (Lim, 2002). Organizational deviance, or counter-normative behaviours are initiated by employees which target employers (Robinson \& Bennett, 1995) and range from 
misdemeanours such as dishonesty (Grover, 1993) and rumour-mongering (Skarlicki \& Folger, 1997), to absenteeism (Goldberg \& Waldman, 2000) and other more serious transgressions such as aggression at the workplace (Dekker, Greenberg, \& Barling, 1998), and employee theft (Greenberg \& Scott, 1996). Cyberloafing is categorized under the rubric of production deviance, which includes relatively minor, albeit, still organizationally harmful misbehaviours.

Cyberloafing has been found to have debilitating effects on employee time, efficiency, organizational commitment and effective functioning of organizations (Dahling, Whitaker, \& Levy, 2009). One study found that $30 \%$ of the companies surveyed were losing more than a day's work per week from employee's cyber activities (Greenfield \& Davis, 2002). In the UK, the costs of wastage due to personal internet usage has been estimated to be $£ 38,000$ per year for an organization, and approximately $£ 11.2$ billion per year for the UK economy (Bloxx, 2008). In a recent survey of over two thousand employed Americans, 62 percent of employees reported spending some of their workday on social networking websites, and 10 percent indicated that they spend 30 percent or more of their workday on these sites (Mercado et al., 2017).

The extent of employee time losses as well as associated costs has alarmed organizations and consequently sparked a growing interest among both scholars and practitioners who seek to identify mechanisms to reduce or avoid these costly employee behaviours. However, despite the debilitating effects of cyberloafing, our understanding of its antecedents remains limited (Cole, Walter, Bedeian, \& O’Boyle, 2012; Greenbaum, Hill, Mawritz, \& Quade, 2017; Liberman, Seidman, Mckenna, \& Buffardi, 2011).

Of the available studies examining the antecedents of cyberloafing, stressors, injustice perceptions toward the organization, external locus of control, sleep deprivation, and workplace norms supporting cyberloafing have been found to augment loafing (Henle \& Blanchard, 2008; Krishnan, Lim, \& Teo, 2010; Lim, 2002; Blau, Yang, \& Ward-Cook, 2006). It is also found that employees who feel powerless in their work environment are more likely to engage in interactive forms of cyberloafing, including playing games. In contrast, job satisfaction and involvement and organizational justice perceptions are identified as restraining cyberloafing (Liberman et al., 2011; Lim, 2002). However, studies integrating the role of supervisor's day-to-day behaviours and personal factors on cyberloafing are missing. This is astonishing in that supervisor style and individuals' personal resources have been found to significantly predict job attitudes over a time span (Staw \& Ross, 1985). To address the current gaps, this study concomitantly examines the role of supervisory perceived communication styles and personal factors as well as on cyberloafing.

\subsection{Supervisors Communication Style and Cyberloafing}

Communication style is defined as a cognitive process that entails micro behaviour in order to make a macro level judgement (Raynes, 2001). It consists of verbal and non-verbal messages. Verbal messages constitute of the choice of words, along with the tone, speech rate, volume and tonality of the voice and non-verbal cues range from body language, gestures, posture, eye contact and movements (Lwehabura \& Matovelo, 2000). The purpose of communication is to get literal meaning across, contributing to task completion, in the process of working with and through others (Kirtley \& Weaver III, 1999; Norton, 1983). Supervisory communication support or lack of it and can determine the extent to which subordinates become motivated and committed in fostering extra-role behaviours (Conger, 1991). 
Researchers over the last few decades have classified communication styles in various ways. One of the most well researched and parsimonious frameworks of CS, which is used in this study, is one proposed by Heffner (1997) who grouped the communication styles into three types- aggressive, passive, and assertive.

Aggressiveness CS: Aggressive communicators are perceived to be poor listeners often expressing their feelings and opinions in a way that violates the rights of others, manifesting competition, criticism, interruptions, and impatience for others' perspectives, often shouting and in some cases even resorting to physical aggression. Aggressive communicators are concerned with moving things in their own way and in preserving their own status and power over employees (Newbold, 1997). Employees working with such supervisors do not experience psychological safety and may thus be discouraged to express their emotions or share burdensome thoughts (Cooper et al., 2003). As a result, aggressive supervisors are perceived less favourably with regard to liking (Myers \& Johnson, 2003), social attractiveness, friendliness, attentiveness (Kassing, Pearce, \& Infante, 2000) and responsiveness. Aggressive supervision has been linked to subordinates' deviance, job dissatisfaction and organizational commitment (Infante \& Gorden, 1987)

Assertive CS: Assertive communicators believe in two-way communication and come across as honest, objective, tolerant and open with high respect for self and others (Lwehabura \& Matovelo, 2000). They stand up for themselves without denying rights of others (DelgadoRomero, Flores, Gloria, Arredondo, \& Castellanos, 2003). They express their thoughts and feelings clearly, they also listen attentively to others concerns and views, signalling interest and building trust (Lwehabura \& Matovelo, 2000). This form of communication builds strong, balanced, and respectful relationships with others and motivates subordinates to go beyond call of their duty and be engaged in assigned tasks.

Passive CS: Supervisors perceived as passive communicators usually go along with other ideas and try to avoid conflict. They are sometimes described as "people pleasers" and are usually unable to convey the full thrust of their message. They feel shy to express their opinion and tend to share limited information and ask limited questions. Such supervisors emphasize solely on fulfillment of affiliation goals, and in maintaining harmony, often causing irritation, delays, and rework.

Drawing from the conservation of resource theory (Hobfoll, 1989), this study examines the impact of three CS- aggressive, assertive and passive on cyberloafing.

Supervisors perceived to be assertive, fulfil employee's implicit expectation to be heard and respected for his/her views enhancing subordinates' self-beliefs and confidence and helping them adapt to their work environment. We posit that interactions with such supervisors creates positive gain spiral which enhances employee's motivation and discourages them from engaging in deviant behaviours, like cyberloafing (Bushra, Ahmad, \& Naveed, 2011).

Contrarily, supervisors engaging in an aggressive CS may be perceived to be socially and emotionally less supportive and approachable (Penney \& Spector, 2005). Commensurate to $\mathrm{COR}$, to conserve resources or to avoid additional loss of resources, subordinates may prefer to avoid aggressive supervisors and engage in withdrawal behaviours like cyberloafing. Similarly, passive supervisors who do not clearly put forward their ideas and thoughts, may fail to motivate employees to go beyond the call of their duty, which in turn demotivates them (Newcombe \& Ashkanasy, 2002). Inability to converse and lack of intellectual stimulation from 
a supervisor may result in employees disengaging and withdrawing from actively contributing to organization (Avolio \& Bass, 1995). Therefore, the following hypotheses are proposed:

Hypothesis 1a. Supervisor's perceived assertive communication style will be negatively related to cyberloafing

Hypothesis $1 b$. Supervisor's perceived aggressive communication style will be positively related to cyberloafing

Hypothesis 1c. Supervisor's perceived passive communication style will be positively related to cyberloafing

\subsection{Supervisory Communication Style and PsyCap}

PsyCap is defined as an individual's positive psychological state of development characterized by: (1) having confidence (efficacy) to take on and put in the necessary effort to succeed at challenging tasks; (2) making a positive attribution (optimism) about succeeding now and in the future; (3) persevering towards goals, and when necessary, redirecting paths to goals (hope) in order to succeed; and (4) when beset by problems and adversity, sustaining and bouncing back and even beyond (resilience) to attain success (Luthans, Avolio, et al., 2007). The common theoretical thread running through the four components of PsyCap (i.e., efficacy, optimism, hope, and resilience) is the "positive appraisal of circumstances and probability for success based on motivated effort and perseverance" (Luthans, Avolio, et al., 2007).

Traditionally, the four resources - hope, optimism, efficacy, and resiliency, have been examined as theoretically independent of each other and assessed through distinct measures. However, empirical research in recent years has established the need for combination of these four factors and examining them simultaneously, rather than assessing them separately (Avey, Luthans, Smith, et al., 2010). This study examined all the four dimensions of PsyCap simultaneously.

Although PsyCap is agentic and internalized, it is not devoid of social mechanisms and may vary on the basis of contextual conditions (Luthans \& Youssef-Morgan, 2017). Social support is an integral mechanism for building employee personal resources. Studies indicate that support from immediate leader behaviours directly affect subordinate perception of safety, appropriate behaviour and judgment and strengthen employee psychological capital and work performance (Lind \& Tyler, 1988). On the basis of COR theory (Hobfoll, 1989), we further examine the effect of three CS of supervisors on PsyCap and cyberloafing. Assertive CS indicates support, care and concern for the subordinate and develops feeling of hope in subordinates. By providing guidelines for desired work behaviours and attitudes, subordinates working with assertive supervisor (Rego \& Pina e Cunha, 2008) strengthen employees' efficacy beliefs. A sense of optimism is also strengthened by the presence of opportunities to be part of decisions making process (e.g., (Carlson, Ferguson, Hunter, \& Whitten, 2012). Positive supervisory behaviour creates a safe environment encourage others to seek help, encourage others, report problems and bounce back even after encountering failures (Edmondson, 1999), building their resilience. Overall, working with such supervisors has a positive effect on subordinates and builds their personal resources (Walumbwa \& Schaubroeck, 2009).

Contrarily, persistent exposure to such negative supervisory behaviour in form of aggressive and passive CS of the supervisor, makes employees less optimistic about accomplishing their 
goals (Karatepe, 2014). Embedded in an environment of negativity, employees often begin to appraise things around them from a negative perspective and lose hope and optimism (Avey, Reichard, Luthans, \& Mhatre, 2011). Overtime, such negative experiences shifts employees perceived locus of causality from internal to external sources, reducing their self-efficacy. Employees working under aggressive supervisors may lead to development of psychological paranoia characterized by feelings of distrust, anxiety, and fear hypervigilance and rumination (Chan \& McAllister, 2014). Such employees will have short resilience and may not be able to bounce back easily. Employees in unsupportive work environment may not feel safe disclosing their failures and reframing such occasions as learning.

Finally, supervisors with passive CS are perceived not to have the skills and confidence to challenge subordinate's ambiguity and misunderstanding (Newbold, 1997). They are unable to discuss and create mutual understanding and support by directing subordinates in fulfilling objectives (Lwehabura \& Matovelo, 2000), the latter experience stress. Lack of social support and opportunities to communicate decreases subordinate's resiliency (Coutu, 2002), their confidence to cope and bounce back from failures and adversity (Luthans, Avolio, et al., 2007). Subordinates experiencing a passive (unclear) or aggressive communication, overtime, may experience a feeling of "being overextended and depleted of one's emotional and physical resources and personal resources" (Maslach \& Leiter, 2008), resulting in experiencing lack of personal resources.

Informed by these extant researches and anchored in COR theory, we examine the association between communication styles. This study proposes the following hypothesis:

Hypothesis 2a. Supervisor's perceived assertive communication style will be positively related to PsyCap.

Hypothesis 2b. Supervisor's perceived passive communication style will be negatively related to PsyCap.

Hypothesis 2c. Supervisor's perceived aggressive communication style will be negatively related to PsyCap.

\subsection{PsyCap-Cyberloafing}

Empirical results have yielded support for strong associated of PsyCap with performance (Luthans, Avolio, et al., 2007). By nature, people with high PsyCap have greater goal-directed energy and achievement orientation and invest considerable resources towards the completion of work tasks. Using positive cognition and motivational processes such individuals harness their behaviours to complete tasks and do not get easily distracted from work (like engaging in cyberloafing). In addition, such individuals tend to employ high selfregulatory motivation as well as emotion control strategies (e.g., self-set goals, controlling negative emotions, re-evaluating negative stimuli in work and nonwork settings) to avoid workplace distractions (Yang \& Chang, 2008). With these characteristics, we expect those high on PsyCap to fulfil their obligations in the workplace and be less distracted and cross the line to engage in cyberloafing in the workplace.

Next, the individual components of PsyCap can specifically be contrasted with deviance (Norman, Avey, Nimnicht, \& Graber Pigeon, 2010). Hope is driven towards the twin positive outcomes of goal accomplishment and finding ways to accomplish individual and organizational goals (Snyder, 2002). By nature, then, cyberloafing is contrary to these goals and therefore such behaviours are not normally exhibited by those high in hope. Resilience is 
directed toward positive adaptation in the face of adversity. Therefore, those high in resilience are looking for positive reactions and adaptations, not negative emotions and cynicism. Hence, cyberloafing is clearly not in the category of positive adaptations and therefore are not likely by those high in resilience. Self-efficacy is directed toward gathering the needed motivation and confidence toward succeeding at a given task. In opposition, cyberloafing behaviours are clearly behaviours that are aimed more toward demotivation of an individual relative to organizational goals. Given that cyberloafing is by nature are geared toward a negative result, they are clearly not behaviours normally displayed by people high in optimism.

Taken together, we propose that individuals high in PsyCap have more resources to draw upon to pursue goals (Hobfoll, 2002a) and their ability to self-control will play an important role in the self-regulation process and such individuals are less likely to lack focus in their job and cyberloaf. Thus, we propose

Hypothesis 3: PsyCap will be negatively related with cyberloafing

\subsection{Mediating role of PsyCap}

PsyCap has emerged as an important mediating variable in the leadership literature. Evidence shows that PsyCap can be modulated by features of the organizational environment (Luthans et al. 2007). In particular, research has shown that effective leadership styles promote PsyCap among employees, and this in turn improves job performance (Rego, Sousa, Marques, \& e Cunha, 2012). For instance, PsyCap has been found to mediate the relationship between perception of transformational leadership and citizenship behaviours (Gooty, Gavin, Johnson, Frazier, \& Snow, 2009). Gooty et al. (2009) found that PsyCap fully mediated the relationship between transformational leadership and organizational citizenship behaviours (OCBs). Two other studies (Rego, Sousa, Marques, \& e Cunha, 2012) examined the mediating effects of PsyCap in the authentic leadership and work outcomes. Recently, Karatepe and Talebzadeh (2016) found that servant leadership influences work engagement through PsyCap. PsyCap has also been examined as an underlying mechanism in stress-outcome relationship (Liao \& Liu, 2015; Liu et al., 2012). Only recently other studies (Agarwal, 2018; Wu \& Lee, 2016) found that psychological capital mediates the relationship between abusive supervision and knowledge sharing. Taken together, we posit that assertive CS of supervisors build personal resources which in turn is negatively related to cyberloafing. Aggressive and passive CS of supervisors, discourage personal resources which in turn encourage deviant behaviours like cyberloafing (Henle \& Blanchard, 2008), which functions as an 'office toy' that offers employees temporary respite from work demands (Anandarajan \& Simmers, 2005). Premised on COR theory, we posit that communication style of supervisors impacts their personal resources- replenishes or drains, which in turn influence employees cyberloafing behaviours (Liu, Chang, Fu, Wang, \& Wang, 2012; Tuckey \& Neall, 2014).

Hypothesis 4: PsyCap mediates the relationship between abusive supervision and cyberloafing

\section{Methods}

\subsection{Sample and Procedures}

Human resource heads of 14 organizations were approached. Initially, we interacted personally with the HR managers of each company, and delivered a presentation to them, which included an explanation of the need and significance of the study with the emphasis on its managerial implications. Seven organizations gave permission to conduct the survey. These 
organizations were -a Textile company, Pharmaceutical Company, Chemical Company, Cement Company, Steel Company, Mining Company and an IT/ITES company. Participating organizations were provided with all the details regarding the survey process.

Seven HR managers agreed to send an invite to their full-time employees to volunteer for participation and interact in the process. Employees who volunteered came together in the company meeting room where researchers explained the need and importance of the study plus the survey procedures and assured them confidentiality of participants. The completed questionnaires were directly mailed to the researchers (through e-mail) without the management's participation in order to decrease the authority influence over participants.

Data were collected in two stages- Time 1 and Time 2. In Time 1, respondents were asked to provide the demographic information and perceived communication style of their supervisors. After two weeks, the second stage (Time-2), we conducted the second-phase survey, following the same procedures as in Time-1. Respondents provided their ratings on PsyCap and cyberloafing. Every questionnaire was marked with a unique code which was recorded in a master file such that the responses received from the two phases can be matched. In time 1, we distributed questionnaires to 1200 full-time employees and received 800 completed questionnaires, representing the response rate of $66.0 \%$. In the second stage, we received 680 completed and usable questionnaires, representing an overall response rate of $56 \%$. The data were screened for outliers and missing data. Within the sample, $76.3 \%$ were male and $23.7 \%$ aged from 28 to 65 . Sixty-eight percent worked for their companies for more than 3 years and $27.2 \%$ had a university degree or above.

\subsection{Measures}

Unless otherwise indicated, all measures used a response scale ranging from 1, which was 'strongly disagree', to 5, which was 'strongly agree'.

Perceived managerial communication styles. Perceived managerial communication styles had three dimensions: passive, aggressive, and assertive and was measured by using instrument developed by Brigham Young University (2004) (appended). Each dimension was assessed on eight items. All the items of three styles were positively keyed. The items of the scale were arranged randomly to assess the three styles, which supervisors is perceived to employ when interacting with their employees. Employees were asked to indicate the extent to which each statement was true regarding their immediate superiors' communication style. Sample item on passive communication style include, "My supervisor lets other people take unfair advantage of him/her"'". Sample items on aggressive communication style include, "My supervisor often ignores another person's rights", and "My supervisor often monopolises conversations". Sample items on assertive communication style include, "My supervisor is able to recognize and express his good points".

Psychological Capital (PsyCap). We measured PsyCap using the 12-item scale adopted from Luthans, Avolio, et al., (2007). The scale included three items each for the four dimensions of PsyCap Scale- self-efficacy, optimism, hope, and resilience. Some sample items are (a) efficacy, "I feel confident helping to set goals in my work area.' (b) hope, "Right now I see myself as being pretty successful at work." (c) resilience, "I usually take stressful things at work in stride."; and (d) optimism, "I always look at the bright side of things regarding my job. 'The 12 items were averaged to form a single measure of PsyCap and to reflect its nature as the higher-order construct of the four dimensions. All items were measured on a six-point scale. 
Cyberloafing was measured by using 11-item scales developed by Lim (2002). Respondents were asked to indicate how often they had engaged in cyberloafing over the past month using a scale ranging from $1=$ never to $5=$ constantly. Examples from the 11 -item measure of cyberloafing include "Browsing investment related websites," and "Checking non-workrelated e-mail."

\subsection{Control Variables}

We controlled for variables that might influence cyberloafing behaviour. Respondents' gender (coded as $0=$ male, $1=$ female) was controlled for because men are more likely to engage in cyberloafing than women (Lim \& Chen, 2009). Age was controlled because it has been found that individuals in their late 20s to early 30s are more likely to use the Internet (Reed, Doty, \& May, 2005). Also, educational level was controlled, because highly educated employees might have been more exposed to Internet usage. Educational level was measured as $1=$ middle school graduate, 2 = high school graduate, $3=2$-year college graduate, $4=4$-year university graduate, and $5=$ master's degree or higher.

\subsubsection{Test for Common Method Variance (CMV)}

Since the data for this study were obtained from a single survey, common method variance (CMV) was possible. To control for the influence of CMV in our study, we followed established remedial and statistical steps. Based on literature recommendations (Podsakoff, MacKenzie, Podsakoff, et al., 2003) we used established scales only, explained the procedures to our participants and guaranteed anonymity. Furthermore, we used filler items and different instructions to create a psychological separation between the sets of variables. We also conducted a series of confirmatory factor analyses and calculated various fit indices to determine how the model fitted our data (Hair, 2005). Moreover, data were collected with a gap of two weeks to avoid social desirability and common method bias. Conventionally, the $\mathrm{x} 2$ /df values less than 2.5 indicate a good fit (Arbuckle 2006). Comparative Fit Index (CFI), Non-normed Fit Index (NFI), Goodness of Fit Index (GFI) and Root mean square error of approximation (RMSEA) were additionally considered to assess the model fit. Hu and Bentler, (1999) suggested that for CFI, NFI, and GFI, values of 0.90 and above indicate good fit. SRMR values below 0.08 suggest an acceptable model fit. For RMSEA, values less than 0.05 generally indicate good fit, while values between 0.05 and 0.08 suggest acceptable fit (Kline, 2005). The proposed five-factor (Abusive supervision, PsyCap, LMX, turnover intentions and stress) hypothesized model, yielded an acceptable fit to the data $(\chi 2=642, \mathrm{df}=252, \chi 2 / \mathrm{df}=2.5, \mathrm{CFI}=.93$, GFI=0.96, NFI=0.95, RMSEA=0.04). The fit of alternative models presented in Table 4 were inferior to that of the hypothesized five-factor. Further, Harman's single-factor test was utilized to investigate potential CMV among the study variables (Podsakoff, MacKenzie, Lee, et al., 2003). The basic assumption of Harman's single-factor test is that if a substantial amount of CMV is present, one general factor will account for the majority $(>50 \%)$ of the covariance among the variables. The results of this test showed that multiple factors were extracted and the first factor accounted for only $34.8 \%$ of the total variance, suggesting CMV could be partially mitigated. 


\begin{tabular}{|c|c|c|c|c|c|c|c|c|c|c|c|c|c|}
\hline & $\alpha^{\mathrm{a}}$ & $\mathrm{CR}^{\mathrm{b}}$ & M & SD & 1 & 2 & 3 & 4 & 5 & 6 & 7 & 8 & 9 \\
\hline 1. Age & & & 25.3 & 8 & 7.3 & & & & & & & & \\
\hline 2. Gender & & & .81 & .32 & .213 & 1 & & & & & & & \\
\hline 3. Education & & & .6 & 7 & .213 & -0.009 & 1 & & & & & & \\
\hline 4. Job Tenure & & & 8.7 & 4.5 & 5.61 & 0.017 & -0.03 & 1 & & & & & \\
\hline 5. Cyberloafing & .81 & .89 & 4.5 & 4.3 & 0.334 & 0.001 & 0.019 & $.078 * *$ & $1(.79)$ & & & & \\
\hline 6. Passive comm & .70 & .81 & 4.2 & 5.1 & 0.313 & $-.113^{* *}$ & -0.049 & -0.013 & $.117 * *$ & $1(.75)$ & & & \\
\hline 7. Aggressive comm & .81 & .86 & 4.7 & 4.5 & .565 & $-.066^{*}$ & -0.031 & -0.009 & $.082 * *$ & $-.469^{* *}$ & $1(.89)$ & & \\
\hline 8.Assertivecom & .83 & .92 & 4.9 & 3.8 & .236 & $.091 * *$ & 0.014 & 0.038 & $-.245^{* *}$ & $-.384 * *$ & $.541 * *$ & $1(.85)$ & \\
\hline 9.PsyCap & .93 & .88 & 5.1 & 3.1 & -0.64 & $.231 *$ & .231 & .432 & $-.346^{* *}$ & $-.230 * * *$ & $-.451^{* *}$ & $.560 * *$ & $1(.93)$ \\
\hline
\end{tabular}

a. $\alpha$ : Cronbach Alpha Reliability; b. CR: Composite Reliability of the construct measures

Average Variance Extracted (AVE) for each construct (nos. 4-8) is provided in parentheses along the diagonal;

Values below the diagonal are inter-construct correlations; values above the diagonal (i.e. AVE) are square of correlations (nos. 4-8).

${ }^{* *} \mathrm{p}<.01$ (two-tailed); ${ }^{*} \mathrm{p}<.05$ (two-tailed); $\mathrm{N}=680$

Table 1 Descriptive Statistics and Inter-Construct Correlations 


\subsubsection{Analytic approach}

Assessment of data was done using AMOS 20. The correlation matrix, means and standard deviation are found in Table 1. Cronbach's $\alpha$ values for all the scales are estimated above 0.70 .

\subsubsection{Measurement model analysis}

Measurement model was evaluated by conducting confirmatory factor analysis (CFA) to analytically check how distinct the constructs were from one another. It was expected that the items would load on their respective constructs only. Conventional fit indices were considered to assess the model fit: goodness-fit index (GFI), adjusted goodness-of-fit index (AGFI), normed fit index (NFI), and root mean square error of approximation (RMSEA). Values between 0.8 to 0.9 for GFI, AGFI, and NFI can be accepted (Hu \& Bentler, 1999) and values beyond 0.9 indicate excellent model fit. Values less than 0.05 for RMSEA indicate an excellent fit for the model whereas values within 0.06 and 0.09 signify an acceptable fit. Confirmatory factor analysis (CFA) was applied using AMOS 20 to analyse the measurement model. CFA results yielded a very good model fit $(\chi 2=605.4$, degrees of freedom $(\mathrm{df})=423$, GFI $=0.91$, AGFI $=0.90, \mathrm{NFI}=0.92, \mathrm{IFI}=0.98, \mathrm{CFI}=0.97, \mathrm{RMSEA}=0.03$, confidence interval $(\mathrm{CI})=0.05-0.07)$. The loading estimates ranged from 0.70 to 0.79 for aggressive communication, .71 to .88 and .70 to .92 for passive and assertive communication, respectively, .71 to .79 for PsyCap and; 0.70 to 0.88 for cyberloafing. When observed variables of the construct correlate with each other, as per the theoretical foundation, it represents a convergent validity. High composite reliability and significant loadings signify convergent validity (Cable \& DeRue, 2002) as shown in Table 2. The results indicated that the model adaptability was satisfactory.

Discriminant validity was also tested to determine the extent of distinctness for each construct (Fornell \& Larcker, 1981). Table 2 shows the correlations among the constructs, which were smaller than the square roots of the AVE in each dependent and independent construct. This effectively supports the discriminant validity of the model. Further, the values of the maximum shared variance (MSV) and average shared variance (ASV) were put together with the AVE values. According to Hair et al. (2010) if all ASV and MSV values are less than their respective AVE values, discriminant validity prevails. Table 2 confirmed the stated condition for defining discriminant validity.

Because we took data from more than one organization, a breach of an assumption of observations independence may occur. Therefore, we carried out one-way analysis of variance (ANOVA), inter-reliability (rwg statistic) and intra-class correlation (ICC) tests to analyse whether the systematic between-group variance in employee cyberloafing was present (Chen \& Bliese, 2002) ANOVA res. ult ( $F=0.363, n s)$, rwg statistic (0.33) and ICC (1)(0.03) values for employee $\mathrm{COB}$ reported no systematic between-group variance in employee cyberloafing. 


\begin{tabular}{|c|c|c|c|c|c|c|}
\hline Variable & $\begin{array}{c}\text { No of } \\
\text { Original } \\
\text { Items } \\
\end{array}$ & $\begin{array}{c}\text { No of } \\
\text { Retained } \\
\text { Items } \\
\end{array}$ & $\begin{array}{l}\text { Standardised } \\
\text { Loadings }\end{array}$ & AVE & MSV & ASV \\
\hline \multirow{8}{*}{$\begin{array}{c}\text { Aggressive } \\
\text { Communication }\end{array}$} & \multirow{8}{*}{8} & \multirow{8}{*}{8} & $.72^{* * *}$ & \multirow{8}{*}{0.89} & \multirow{8}{*}{0.78} & \multirow{8}{*}{0.72} \\
\hline & & & $.70^{* * *}$ & & & \\
\hline & & & $.46^{* * *}$ & & & \\
\hline & & & $.79^{* * *}$ & & & \\
\hline & & & $.76^{* * *}$ & & & \\
\hline & & & $.77^{* * *}$ & & & \\
\hline & & & $.76^{* * *}$ & & & \\
\hline & & & $.78^{* * *}$ & & & \\
\hline \multirow{8}{*}{$\begin{array}{c}\text { Assertive } \\
\text { Communication }\end{array}$} & \multirow{8}{*}{8} & \multirow{8}{*}{8} & $.92^{* * *}$ & \multirow{8}{*}{0.85} & \multirow{8}{*}{0.76} & \multirow{8}{*}{0.71} \\
\hline & & & $.87^{* * *}$ & & & \\
\hline & & & $.70^{* * *}$ & & & \\
\hline & & & $.74^{* * *}$ & & & \\
\hline & & & $.77^{* * *}$ & & & \\
\hline & & & $.76^{* * *}$ & & & \\
\hline & & & $.73^{* * *}$ & & & \\
\hline & & & $.76^{* * *}$ & & & \\
\hline \multirow{9}{*}{$\begin{array}{c}\text { Passive } \\
\text { Communication }\end{array}$} & \multirow{9}{*}{8} & \multirow{9}{*}{8} & $.76^{* * *}$ & \multirow{9}{*}{0.75} & \multirow{9}{*}{0.71} & \multirow{9}{*}{0.70} \\
\hline & & & $.70^{* * *}$ & & & \\
\hline & & & $.73^{* * *}$ & & & \\
\hline & & & $.82^{* * *}$ & & & \\
\hline & & & $.88^{* * *}$ & & & \\
\hline & & & $.81^{* * *}$ & & & \\
\hline & & & $.71^{* * *}$ & & & \\
\hline & & & $.71^{* * *}$ & & & \\
\hline & & & $.77^{* * *}$ & & & \\
\hline \multirow{12}{*}{ PsyCap } & \multirow{12}{*}{12} & \multirow{12}{*}{12} & $.76^{* * *}$ & & & \\
\hline & & & $.74^{* * *}$ & & & \\
\hline & & & $.76^{* * *}$ & & & \\
\hline & & & $.73^{* * *}$ & & & \\
\hline & & & $.84^{* * *}$ & & & \\
\hline & & & $.81^{* * *}$ & 0.93 & 0.91 & 0.89 \\
\hline & & & $.84^{* * *}$ & 0.93 & 0.91 & \\
\hline & & & $.76^{* * *}$ & & & \\
\hline & & & $.90^{* * *}$ & & & \\
\hline & & & $.94^{* * *}$ & & & \\
\hline & & & $.87^{* * *}$ & & & \\
\hline & & & $.65^{* * *}$ & & & \\
\hline & & & $.76^{* * *}$ & & & \\
\hline & & & $.70^{* * *}$ & & & \\
\hline & & & $.73^{* * *}$ & & & \\
\hline & & & $.82^{* * *}$ & & & \\
\hline & & & $.88^{* * *}$ & & & \\
\hline Cyberloafing & 11 & 11 & $.81^{* * *}$ & 0.79 & 0.75 & 0.72 \\
\hline & & & $.87^{* *}$ & & & \\
\hline & & & $.75^{* *}$ & & & \\
\hline & & & $.86^{* *}$ & & & \\
\hline & & & $.71^{* * *}$ & & & \\
\hline & & & $.75^{* * *}$ & & & \\
\hline
\end{tabular}

${ }^{*} \mathrm{p}<.05$ (two-tailed); ${ }^{* *} \mathrm{p}<.01$ (two-tailed); ${ }^{* * *} \mathrm{p}<0.001 ; \mathrm{N}=680$

Table 2 Scale Reliability and Validity 


\section{Results}

\subsection{Structural modelling}

To test the hypotheses, we examined a series of structural equation models. First, our baseline model is presented as the first model (Model 1), which estimated all of the hypothesized relationships between the current variables. Specifically, we included the direct paths from: assertive, aggressive and passive CS to PsyCap; PsyCap to cyberloafing Table 3 presents the unstandardized coefficients for the structural paths estimated in the model.

It can be seen from Table 3 that assertive, aggressive and passive CS were related to cyberloafing $(\mathrm{B}=-.43, \beta=.11, \mathrm{p}<.01),(\mathrm{B}=.11, \beta=.21, \mathrm{p}<.01),(\mathrm{B}=.23, \beta=.21, \mathrm{p}<.01)$, respectively thereby, supporting hypothesis $1 \mathrm{a}, 1 \mathrm{~b}$ and $1 \mathrm{c}$. Assertive, aggressive but not passive CS were also significantly related to PsyCap $(B=.27, \beta=.21, p<.01),(B=-.37, \beta=-.31$, $\mathrm{p}<.01),(\mathrm{B}=-19, \beta=-.11, \mathrm{p}=\mathrm{ns})$, respectively, thereby, supporting hypothesis $2 \mathrm{a}, 2 \mathrm{~b}$ but not $2 \mathrm{c}$. PsyCap were positively related to cyberloafing $(B=1.27, \beta=.59, \mathrm{p}<.01)$, supporting hypothesis 3.

Next, we evaluated a second model (Model 2) to assess whether PsyCap was a partial or full mediator of the relationship between assertive and aggressive CS and cyberloafing by eliminating the direct path from CS to cyberloafing from Model 1 (i.e. testing a full mediation model). This second model (Model 2) had a better fit the data than model, and also yielded larger information criteria (see Table 3 and 4), suggesting that the full mediation relationship between abusive supervision and cyberloafing was not sufficient to account for the total relationship between these two variables. As such, PsyCap was a partial mediator the relationship between CS and cyberloafing. Then, we tested a non-mediating model by removing the direct path from CS to PsyCap from Model 1. This third model (Model 3) also had a poorer fit to the data than Model 1 and lower information criteria as evidenced by the result presented in Table 3 and 4.

\begin{tabular}{|l|c|c|c|c|c|c|c|c|}
\hline & $\chi \mathbf{2}$ & Df & $\chi 2$ /df & SRMR & GFI & NFI & CFI & RMSEA \\
\hline $\begin{array}{l}\text { Model 1: } \\
\text { PsyCap mediates the relationship between } \\
\text { assertive and aggressive communication and } \\
\text { cyberloafing }\end{array}$ & 552.6 & 200 & 2.7 & .08 & .72 & .86 & .76 & .07 \\
\hline $\begin{array}{l}\text { Model 2: } \\
\begin{array}{l}\text { PsyCap partially mediates the relationship } \\
\text { between assertive and aggressive } \\
\text { communication and cyberloafing }\end{array}\end{array}$ & 303.2 & 246 & 1.2 & .05 & .82 & .96 & .99 & .03 \\
\hline $\begin{array}{l}\text { Model 3: } \\
\text { PsyCap does not mediates the relationship } \\
\text { between assertive and aggressive } \\
\text { communication and cyberloafing }\end{array}$ & 550 & 201 & 2.7 & .06 & .82 & .91 & .83 & .03 \\
\hline
\end{tabular}

**Passive CS was not found to be significantly related with PsyCap, hence not Modelled.

Table 3 Goodness-of-fit indexes

Thus, the results suggested support that in terms of Model fit as well as regression weights, partial mediating model was the best fit, supporting partial mediation, hypothesis 4 . To further assess the significance of the mediation, we applied Sobel's test for indirect effects. Results show that the intervening effect of PsyCap for assertive and aggressive CS with cyberloafing, 
respectively (standardized indirect effect $=.19$, Sobel $\mathrm{t}=5.80, \mathrm{p}<.01$ ); (standardized indirect effect $=.09$, Sobel $\mathrm{t}=3.20, \mathrm{p}<.01$ ) were significant. Taken together, Hypothesis 4 was supported.

\begin{tabular}{|r|l|l|l|l|l|}
\hline \multirow{2}{*}{ Structural path } & \multirow{3}{*}{} & & \multicolumn{3}{|c|}{ Unstandardized path coefficients } \\
\cline { 4 - 6 } & & & \multicolumn{1}{|c|}{ M1 } & \multicolumn{1}{c|}{ M2 } & \multicolumn{1}{c|}{ M3 } \\
\hline Assertive CS & $\longrightarrow$ & Cyberloafing & $-0.435^{* *}$ & $-0.493^{* *}$ & $-0.011^{*}$ \\
\hline Aggressive CS & $\longrightarrow$ & Cyberloafing & $0.119^{* *}$ & $0.267^{* *}$ & $0.210^{*}$ \\
\hline Passive CS & $\longrightarrow$ & Cyberloafing & $.230^{* *}$ & $0.101^{*}$ & $0.011^{*}$ \\
\hline PsyCap & $\longrightarrow$ & Cyberloafing & $0.384^{* *}$ & $0.427^{* *}$ & \\
\hline Assertive CS & $\longrightarrow$ & PsyCap & $0.270^{* *}$ & $0.345^{* *}$ & \\
\hline Aggressive CS & $\longrightarrow$ & PsyCap & $-0.371^{* *}$ & $-0.421^{* *}$ & \\
\hline Passive CS & $\longrightarrow$ & PsyCap & $-0.190(\mathrm{~ns})$ & -0.111 & \\
\hline
\end{tabular}

** $\mathrm{p}<.01$ (two-tailed); ${ }^{*} \mathrm{p}<.05$ (two-tailed); $\mathrm{N}=680$

Table 4 Unstandardized path coefficients

\section{Discussion}

Understanding (mis)use of technology is a timely, given its crippling effects on employee and organizational productivity.

The purpose of the current study was to examine the impact of perceived communication style of supervisor and PsyCap on cyberloafing. The study also examined the mediating effect of PsyCap in perceived CS of supervisors and cyberloafing. The results suggest that CS of supervisors-aggressive, assertive and passive as well as subordinates PsyCap relate to cyberloafing, and the relationship is partially mediated by PsyCap for the former two styles (aggressive and assertive). This study of this study advances body of knowledge in the domain of Cyberloafing, Communication style as well as PsyCap. Despite the diverse studies associated with cyberloafing, a review of the literature suggests that researchers investigating the organizational processes leading to cyberloafing have been ignored. Though previous studies have provided valuable insights into role of leadership styles and employee outcomes, one major oversight of the existing research is that the impact of social interactions between supervisors and subordinates that captures the degree to which people are treated on a regular basis.

This study tested a well-established and systematic framework to study employee responses to cyberloafing that has not been examined in the context of communication styles of the supervisor. This study also examines the role of PsyCap as an underlying mechanism in the leadership-cyberloafing relationship. This study is also one of the first one to concomitantly examine the impact of supervisor's communication styles as well as personal resources on cyberloafing.

The findings of this research also provide a communication lens through which to examine the existence of a positive and negative aspects of leader behaviour within the workplace (Rook, 1998). By including the influence of PsyCap, the study moves the discourse one step forward with a specific focus on considering impact of leaders' communication style on followers' psychological reactions that translate leadership behaviours into unfavourable behavioural outcomes. 
By examining the mediating role CS on PsyCap and its effects on cyberloafing, the study adds to the positive organizational behaviour literature which has gained prominence in the organizational sciences and emphasis on managing employees' positive psychological capital (PsyCap; see (Luthans, Avolio, et al., 2007). Despite emerging empirical work on PsyCap, Luthans et al. noted that much remains to be done, especially in examining not only the effects of PsyCap, on a range of important work outcomes, but also its antecedents. This study delineates a more comprehensive map of the precursors, intervening mechanisms and outcomes of PsyCap. The study also provides replication and extension of previous work linking PsyCap and deviance (Luthans, Avolio, et al., 2007; Norman et al., 2010) by showing in a separate sample that the relationship between these constructs can be replicated and that this relationship depends on social exchange quality. This study adds to PsyCap literature by examining all the four core dimensions simultaneously, since such efforts are limited

\subsection{Managerial Implications}

From a managerial standpoint, new knowledge about predictors of cyberloafing can help practitioners design interventions for managing such deviance behaviours.

Whereas supervisors are often unable to directly influence an organization's policies and practices, they are typically free to determine the extent to which they treat their employees with dignity, respect, and truthfulness, offer clear explanations for their actions, and show concern for them (Scott et al. 2014). Thus, supervisors should be respectful in communication when interacting with employees for avoiding negative outcomes. Research suggests that negativity bias, described as a condition in which the psychological impact of negative events tends to be longer lasting and have a greater influence on a person's state of mind than do positive events (Rook, 1998).

The finding of this study can also be examined from cultural lens. Employees in collectivist cultures attach greater importance to organization hierarchy (Varma, Pichler, \& Srinivas, 2005). People in such societies possess greater associative needs and look up to supervisors for support, protection, and guidance much more than employees in western cultures (Tripathi, 1990; Vidyarthi, Liden, Anand, Erdogan, \& Ghosh, 2010). Immense emphasis is placed on the quality of communication and dialogue from early years of rearing and socialization. An oftenrepeated discourse at Indian homes and school is- shabd sambhal boleyee, shabd ke haath na paanv. Ek shabd aushadh kare, ek shabd kare ghaav. (Tulsi Das) (One should use words carefully as they don't have arms or feet of their own. A word can serve as a balm or become a scar). This indicates the seriousness of communication as a virtue in Especially in the Indian context (Srite, 2006). Given the importance of relationship the with the supervisor, the latter's communication style will have intense and pronounced effects on one's self worth, personal resources as well as attitudes and behaviour.

Therefore, the effects of a verbally aggressive and passive communication will likely have a greater negative impact on an employee's well-being than would a positive event.

This study reiterates the importance of the two most important management secrets of employee productivity-Pygmalion and Galatea effect. Others' expectations (supervisors) of employees and their expectations of themselves are the key factors in how well people perform at work. Known as the Pygmalion effect and the Galatea effect, respectively, the power of expectations cannot be overestimated. The Pygmalion effect was described by Livingston even earlier in the September/October 1988 Harvard Business Review. "The way managers treat their 
subordinates is subtly influenced by what they expect of them," Livingston said in his article, Pygmalion in Management. Livingston went on to say about the supervisor, "If he is unskilled, he leaves scars on the careers of the young men (and women), cuts deeply into their self-esteem and distorts their image of themselves as human beings. The findings of the study have implication for academicians as well as managers. Academics institutes should design programs to create awareness of the impact of their style on subordinates, especially since it can have important implications on team motivation (Fujimoto, Härtel, \& Azmat, 2013; Omilion-Hodges \& Baker, 2013). Interventions should be designed to train budding managers in effective communication skills. As a managerial implication, organizations can conduct training programs to make their managers aware of the impact of their style of communication on subordinate's personal resources as well as organizational productivity. Communication effectiveness among supervisors can be promoted through emotional intelligence training (Moliner, Cropanzano, \& Martínez-Tur, 2017) and employee assistance programs which focus on teaching employees to manage their negative emotions and better cope with negative situations.

Given the importance of PsyCap in lowering cyberloafing, organizations should pay attention to screening for personal resources in addition to knowledge, skills, and abilities. Recent studies show that overall PsyCap is malleable and can be developed in short training interventions with employees (Luthans, Avolio, et al., 2007). Interventions customized to develop employee's personal resources may help organizations to address the impact of supervisor communication.

\subsection{Limitations and Future Research}

In this study we integrate communication and leadership literature to examine the effect of perceived communication style of supervisor in cyberloafing. Despite substantive theoretical contributions, the study is not without limitations. The cross-sectional design of the study does not allow us to determine causality among variables. This limitation means arrows suggesting association among constructs should not be interpreted as causal relationships, but as associations that suggest causal ordering that should be confirmed with longitudinal research designs. That the alternative model of behaviour demonstrated poor fit suggests alternative causal ordering is unlikely. Only longitudinal research can disentangle cause and effect adequately. Results may partly be influenced by CMV because all data were collected through self-reports.

\section{References}

Akbulut, Y., Dönmez, O., \& Dursun, Ö. Ö. (2017). Cyberloafing and social desirability bias among students and employees. Computers in Human Behavior, 72, 87-95.

Anandarajan, M., \& Simmers, C. A. (2005). Developing human capital through personal web use in the workplace: Mapping employee perceptions. Communications of the Association for Information Systems, 15(1), 41.

Arbuckle, J. L. (2006). Amos (version 7.0)[computer program]. Chicago: SpSS.

Avey, J. B., Luthans, F., Smith, R. M., \& Palmer, N. F. (2010). Impact of positive psychological capital on employee well-being over time. Journal of Occupational Health Psychology, 15(1), 17. 
Avey, J. B., Luthans, F., \& Youssef, C. M. (2010). The additive value of positive psychological capital in predicting work attitudes and behaviors. Journal of Management, 36(2), 430-452.

Avey, J. B., Reichard, R. J., Luthans, F., \& Mhatre, K. H. (2011). Meta-analysis of the impact of positive psychological capital on employee attitudes, behaviors, and performance. Human Resource Development Quarterly, 22(2), 127-152.

Avolio, B. J., \& Bass, B. M. (1995). Individual consideration viewed at multiple levels of analysis: A multi-level framework for examining the diffusion of transformational leadership. The Leadership Quarterly, 6(2), 199-218.

Betts, T. K., Setterstrom, A. J., Pearson, J. M., \& Totty, S. (2018). Explaining cyberloafing through a theoretical integration of theory of interpersonal behavior and theory of organizational justice. In Business Education and Ethics: Concepts, Methodologies, Tools, and Applications (pp. 144-165). IGI Global.

Blau, G., Yang, Y., \& Ward-Cook, K. (2006). Testing a measure of cyberloafing. Journal of Allied Health, 35(1), 9-17.

Brigham Young University (2004), "Assertiveness", available at: http//f2mail.rediff.com/bn/ download.cgi/Assertiveness.htm (accessed 21 December 2017).

Bloxx. (2008). Productivity, Internet abuse, and how to improve one by eliminating the other. Available from: http://www.bloxx.com/assets/downloads/bloxx whitepaper productivit y.pdf, downloaded on $2^{\text {nd }}$ January, 2018

Bushra, F., Ahmad, U., \& Naveed, A. (2011). Effect of transformational leadership on employees' job satisfaction and organizational commitment in banking sector of Lahore (Pakistan). International Journal of Business and Social Science, 2(18).

Cable, D. M., \& DeRue, D. S. (2002). The convergent and discriminant validity of subjective fit perceptions. Journal of Applied Psychology, 87(5), 875.

Carlson, D., Ferguson, M., Hunter, E., \& Whitten, D. (2012). Abusive supervision and workfamily conflict: The path through emotional labor and burnout. The Leadership Quarterly, 23(5), 849-859.

Chan, M. E., \& McAllister, D. J. (2014). Abusive supervision through the lens of employee state paranoia. Academy of Management Review, 39(1), 44-66.

Chen, G., \& Bliese, P. D. (2002). The role of different levels of leadership in predicting self-and collective efficacy: evidence for discontinuity. Journal of Applied Psychology, 87(3), 549.

Cole, M. S., Walter, F., Bedeian, A. G., \& O'Boyle, E. H. (2012). Job burnout and employee engagement: A meta-analytic examination of construct proliferation. Journal of Management, 38(5), 1550-1581.

Conger, J. A. (1991). Inspiring others: The language of leadership. The Executive, 5(1), 31-45.

Cooper, D. R., Schindler, P. S., \& Sun, J. (2003). Business research methods. Retrieved from http://sutlib2.sut.ac.th/sut_contents/H139963.pdf

Coutu, D. L. (2002). How resilience works. Harvard Business Review, 80(5), 46-56. 
Dahling, J. J., Whitaker, B. G., \& Levy, P. E. (2009). The development and validation of a new Machiavellianism scale. Journal of Management, 35(2), 219-257.

De Vries, R. E., Bakker-Pieper, A., \& Oostenveld, W. (2010). Leadership= communication? The relations of leaders' communication styles with leadership styles, knowledge sharing and leadership outcomes. Journal of Business and Psychology, 25(3), 367-380.

Dekker, I., Greenberg, L., \& Barling, J. (1998). Predicting union attitudes in student part-time workers. Canadian Journal of Behavioural Science/Revue Canadienne Des Sciences Du Comportement, 30(1), 49.

Delgado-Romero, E. A., Flores, L., Gloria, A., Arredondo, P., \& Castellanos, J. (2003). The majority in the minority: Developmental career challenges for Latino and Latina psychology faculty. The Majority in the Minority: Retaining Latina/o Faculty, Administrators, and Students in the 21st Century, 257-283.

de Vass, T., Shee, H., \& Miah, S. (2018). The effect of "Internet of Things" on supply chain integration and performance: An organisational capability perspective. Australasian Journal of Information Systems, 22

Edmondson, A. (1999). Psychological safety and learning behavior in work teams. Administrative Science Quarterly, 44(2), 350-383.

Fairhurst, G. T., \& Connaughton, S. L. (2014). Leadership: A communicative perspective. Leadership, 10(1), 7-35.

Fornell, C., \& Larcker, D. F. (1981). Evaluating structural equation models with unobservable variables and measurement error. Journal of Marketing Research, 39-50.

Goldberg, C. B., \& Waldman, D. A. (2000). Modeling employee absenteeism: Testing alternative measures and mediated effects based on job satisfaction. Journal of Organizational Behavior, 665-676.

Gooty, J., Gavin, M., Johnson, P. D., Frazier, M. L., \& Snow, D. B. (2009). In the eyes of the beholder transformational leadership, positive psychological capital, and performance. Journal of Leadership E Organizational Studies, 15(4), 353-367.

Greenbaum, R. L., Hill, A., Mawritz, M. B., \& Quade, M. J. (2017). Employee Machiavellianism to unethical behavior: The role of abusive supervision as a trait activator. Journal of Management, 43(2), 585-609.

Greenberg, J., \& Scott, K. S. (1996). Why do workers bite the hands that feed them? Employee theft as a social exchange process.

Greenfield, D. N., \& Davis, R. A. (2002). Lost in cyberspace: The web@ work. CyberPsychology $\mathcal{E}$ Behavior, 5(4), 347-353.

Grover, V. (1993). An empirically derived model for the adoption of customer-based interorganizational systems. Decision Sciences, 24(3), 603-640.

Hair, J. F., Anderson, R.E, Tatham, R.L., \& Black, W.C.(2005): Multivariate data analysis. Upper Saddle River, NJ: Prentice Hall.

Hair, J. F., Black, W. C., Babin, B. J., \& Anderson, R. E. (2010). Multivariate data analysis: International version. New Jersey, Pearson. 
Hakanen, J. J., Bakker, A. B., \& Jokisaari, M. (2011). A 35-year follow-up study on burnout among Finnish employees. Journal of Occupational Health Psychology, 16(3), 345.

Halbesleben, J. R., \& Bowler, W. M. (2007). Emotional exhaustion and job performance: the mediating role of motivation. Journal of Applied Psychology, 92(1), 93.

Heffner, C.L. (1997), “Communication styles”, available at: www.siu.edu/offices/counsel/ talk.htm\#chart (accessed 8 October 2006).

Henle, C. A., \& Blanchard, A. L. (2008). The interaction of work stressors and organizational sanctions on cyberloafing. Journal of Managerial Issues, 383-400.

Hobfoll, S. E. (1989). Conservation of resources: A new attempt at conceptualizing stress. American Psychologist, 44(3), 513.

Hobfoll, S. E. (2002a). Social and psychological resources and adaptation. Review of General Psychology, 6(4), 307.

Hobfoll, S. E. (2002b). Social and psychological resources and adaptation. Review of General Psychology, 6(4), 307.

Hu, L., \& Bentler, P. M. (1999). Cutoff criteria for fit indexes in covariance structure analysis: Conventional criteria versus new alternatives. Structural Equation Modeling: A Multidisciplinary Journal, 6(1), 1-55.

Infante, D. A., \& Gorden, W. I. (1987). Superior and subordinate communication profiles: Implications for independent-mindedness and upward effectiveness. Communication Studies, 38(2), 73-80.

Karatepe, O. M. (2014). Hope, work engagement, and organizationally valued performance outcomes: an empirical study in the hotel industry. Journal of Hospitality Marketing $\mathcal{E}$ Management, 23(6), 678-698.

Karatepe, O. M., \& Talebzadeh, N. (2016). An empirical investigation of psychological capital among flight attendants. Journal of Air Transport Management, 55, 193-202.

Kassing, J. W., Pearce, K. J., \& Infante, D. A. (2000). Corporal punishment and communication in father-son dyads. Communication Research Reports, 17(3), 237-249.

Kirtley, M. D., \& Weaver III, J. B. (1999). Exploring the impact of gender role self-perception on communication style. Women's Studies in Communication, 22(2), 190-209.

Kline, R. B. (2005). Methodology in the social sciences , (2nd ed.). New York, NY

Krishnan, S., Lim, V. K., \& Teo, T. S. (2010). How Does Personality Matter? Investigating the Impact of Big-Five Personality Traits on cyberloafing. In ICIS (p. 6).

Liberman, B., Seidman, G., Mckenna, K. Y., \& Buffardi, L. E. (2011). Employee job attitudes and organizational characteristics as predictors of cyberloafing. Computers in Human Behavior, 27(6), 2192-2199.

Lim, V. K. (2002). The IT way of loafing on the job: Cyberloafing, neutralizing and organizational justice. Journal of Organizational Behavior, 23(5), 675-694.

Lim, V. K. G., \& Chen, D. J. Q. (2009). Impact of Cyberloafing on Affect, Work depletion, Facilitation and Engagement. In Conference Paper SIOP (pp. 1-20). 
Lind, E. A., \& Tyler, T. R. (1988). The Social Psychology of Procedural Justice. Springer Science \& Business Media.

Liu, L., Chang, Y., Fu, J., Wang, J., \& Wang, L. (2012). The mediating role of psychological capital on the association between occupational stress and depressive symptoms among Chinese physicians: a cross-sectional study. BMC Public Health, 12(1), 1.

Luthans, F., Avolio, B. J., Avey, J. B., \& Norman, S. M. (2007). Positive psychological capital: Measurement and relationship with performance and satisfaction. Personnel Psychology, 60(3), 541-572.

Luthans, F., \& Youssef-Morgan, C. M. (2017). Psychological Capital: An Evidence-Based Positive Approach. Annual Review of Organizational Psychology and Organizational Behavior, 4(1).

Lwehabura, M. J., \& Matovelo, D. S. (2000). Effective library management: issues for managers and subordinates. New Library World, 101(6), 263-269.

Maslach, C., \& Leiter, M. P. (2008). Early predictors of job burnout and engagement. Journal of Applied Psychology, 93(3), 498.

Mayer, D. M., Kuenzi, M., Greenbaum, R., Bardes, M., \& Salvador, R. B. (2009). How low does ethical leadership flow? Test of a trickle-down model. Organizational Behavior and Human Decision Processes, 108(1), 1-13.

Mercado, B. K., Mercado, B. K., Giordano, C., Giordano, C., Dilchert, S., \& Dilchert, S. (2017). A meta-analytic investigation of cyberloafing. Career Development International, 22(5), 546-564.

Morrison, Elizabeth W. "Employee Voice Behavior: Integration and Directions for Future Research." Academy of Management Annals 5, no. 1 (2011): 373-412.(Norton, 1983)

Myers, S. A., \& Johnson, A. D. (2003). Verbal aggression and liking in interpersonal relationships. Communication Research Reports, 20(1), 90-96.

Newbold, T. (1997), “What are communication skills?”, in Scholes, E. (Ed.), Gower Handbook of Internal Communication Part IV, The ITEM group, London, pp. 235-60.

Newcombe, M. J., \& Ashkanasy, N. M. (2002). The role of affect and affective congruence in perceptions of leaders: An experimental study. The Leadership Quarterly, 13(5), 601-614.

Norman, S. M., Avey, J. B., Nimnicht, J. L., \& Graber Pigeon, N. (2010). The interactive effects of psychological capital and organizational identity on employee organizational citizenship and deviance behaviors. Journal of Leadership \& Organizational Studies, 17(4), 380-391.

Norton, R. (1983). Communicator style: Theory, applications, and measures. Sage Publications Beverly Hills, CA. Retrieved from http://library.wur.nl/WebQuery/clc/208125

Penney, L. M., \& Spector, P. E. (2005). Job stress, incivility, and counterproductive work behavior (CWB): The moderating role of negative affectivity. Journal of Organizational Behavior, 26(7), 777-796.

Podsakoff, P. M., MacKenzie, S. B., Lee, J.-Y., \& Podsakoff, N. P. (2003). Common method biases in behavioral research: a critical review of the literature and recommended remedies. Journal of Applied Psychology, 88(5), 879. 
Raynes, B. L. (2001). Predicting difficult employees: The relationship between vocational interests, self-esteem, and problem communication styles. Applied Human Resource Management Research, 6(1), 33-66.

Reed, K., Doty, D. H., \& May, D. R. (2005). The impact of aging on self-efficacy and computer skill acquisition. Journal of Managerial Issues, 212-228.

Rego, A., \& Pina e Cunha, M. (2008). Workplace spirituality and organizational commitment: an empirical study. Journal of Organizational Change Management, 21(1), 53-75.

Rego, A., Sousa, F., Marques, C., \& e Cunha, M. P. (2012). Authentic leadership promoting employees' psychological capital and creativity. Journal of Business Research, 65(3), 429437.

Robinson, S. L., \& Bennett, R. J. (1995). A typology of deviant workplace behaviors: A multidimensional scaling study. Academy of Management Journal, 38(2), 555-572.

Rook, K. S. (1998). Investigating the positive and negative sides of personal relationships: Through a lens darkly?

Scott, R. A., Fall, T., Pasko, D., Barker, A., Sharp, S. J., Arriola, L., Boeing, H. (2014). Common genetic variants highlight the role of insulin resistance and body fat distribution in type 2 diabetes, independent of obesity. Diabetes, 63(12), 4378-4387.

Skarlicki, D. P., \& Folger, R. (1997). Retaliation in the workplace: The roles of distributive, procedural, and interactional justice. Journal of Applied Psychology, 82(3), 434.

Snyder, C. R. (2002). Hope theory: Rainbows in the mind. Psychological Inquiry, 13(4), 249-275.

Srite, M. (2006). Culture as an explanation of technology acceptance differences: An empirical investigation of Chinese and US users. Australasian Journal of Information Systems, 14(1).

Staw, B. M., \& Ross, J. (1985). Stability in the midst of change: A dispositional approach to job attitudes. Journal of Applied Psychology, 70(3), 469.

Tripathi, R. C. (1990). Interplay of values in the functioning of Indian organizations. International Journal of Psychology, 25(3-6), 715-734.

Tuckey, M. R., \& Neall, A. M. (2014). Workplace bullying erodes job and personal resources: Between-and within-person perspectives. Journal of Occupational Health Psychology, 19(4), 413.

Varma, A., Pichler, S., \& Srinivas, E. S. (2005). The role of interpersonal affect in performance appraisal: evidence from two samples-the US and India. The International Journal of Human Resource Management, 16(11), 2029-2044.

Vidyarthi, P. R., Liden, R. C., Anand, S., Erdogan, B., \& Ghosh, S. (2010). Where do I stand? Examining the effects of leader-member exchange social comparison on employee work behaviors. Journal of Applied Psychology, 95(5), 849.

Walumbwa, F. O., \& Schaubroeck, J. (2009). Leader personality traits and employee voice behavior: mediating roles of ethical leadership and work group psychological safety. Journal of Applied Psychology, 94(5), 1275. 
Wheeler, A. R., Halbesleben, J. R., \& Shanine, K. (2010). Eating their cake and everyone else's cake, too: Resources as the main ingredient to workplace bullying. Business Horizons, 53(6), 553-560.

Wu, W.-L., \& Lee, Y.-C. (2016). Do employees share knowledge when encountering abusive supervision? Journal of Managerial Psychology, 31(1), 154-168.

Yang, F.-H., \& Chang, C.-C. (2008). Emotional labour, job satisfaction and organizational commitment amongst clinical nurses: A questionnaire survey. International Journal of Nursing Studies, 45(6), 879-887.

Yukl, G., \& Mahsud, R. (2010). Why flexible and adaptive leadership is essential. Consulting Psychology Journal: Practice and Research, 62(2), 81. 


\section{Appendix}

\section{Questionnaire}

\begin{tabular}{|c|c|c|c|c|c|}
\hline $\begin{array}{l}\text { Please respond to the following statement, indicating your } \\
\text { choice by agreeing or disagreeing ( } 1 \text { - "Strongly disagree", } \\
2 \text { - "Disagree", } 3 \text { - "Neutral", } 4 \text { - "Agree", } 5 \text { - "Strongly } \\
\text { agree") }\end{array}$ & 1 & 2 & 3 & 4 & 5 \\
\hline $\begin{array}{l}\text { 1. My Manager is able to recognize and express his } \\
\text { good points. }\end{array}$ & & & & & \\
\hline $\begin{array}{l}\text { My Manager often brags and makes unrealistic } \\
\text { claims about his good points. }\end{array}$ & & & & & \\
\hline $\begin{array}{l}\text { My Manager feels guilty when he/she stands up for } \\
\text { his/her rights or expresses his/her feelings. }\end{array}$ & & & & & \\
\hline $\begin{array}{l}\text { My Manager makes other people look or feel } \\
\text { stupid, small, or afraid. }\end{array}$ & & & & & \\
\hline $\begin{array}{l}\text { My Manager allows other people to take unfair } \\
\text { advantage of him/her. }\end{array}$ & & & & & \\
\hline $\begin{array}{l}\text { My Manager does not express his/her views and } \\
\text { feelings. }\end{array}$ & & & & & \\
\hline My Manager ignores another person's rights. & & & & & \\
\hline $\begin{array}{l}\text { My Manager is able to express negative feelings } \\
\text { about other people without being abusive or cruel. }\end{array}$ & & & & & \\
\hline $\begin{array}{l}\text { My Manager frequently takes unfair advantage of } \\
\text { other people. }\end{array}$ & & & & & \\
\hline $\begin{array}{l}\text { My Manager is able to receive compliments } \\
\text { without denying them. }\end{array}$ & & & & & \\
\hline $\begin{array}{l}\text { My Manager has difficulty saying "no" when } \\
\text { he/she does not want to say "yes" to someone's } \\
\text { request. }\end{array}$ & & & & & \\
\hline $\begin{array}{l}\text { My Manager often makes unreasonable demands } \\
\text { from other people. }\end{array}$ & & & & & \\
\hline $\begin{array}{l}\text { My Manager usually stands up for his/her rights } \\
\text { and let other people do the same. }\end{array}$ & & & & & \\
\hline My Manager often monopolizes conversations. & & & & & \\
\hline $\begin{array}{l}\text { My Manager has difficulty making reasonable } \\
\text { requests of other people. }\end{array}$ & & & & & \\
\hline $\begin{array}{l}\text { My Manager is able to start or carry on } \\
\text { conversations comfortably. }\end{array}$ & & & & & \\
\hline
\end{tabular}









\section{Psychological capital}

\begin{tabular}{|c|c|c|c|c|c|c|}
\hline $\begin{array}{l}\text { Psychological capital } \\
\text { Please indicate the extent to which you agree with the following } \\
\text { statements "about yourself": } 1=\text { Strongly Disagree }-2 \text { Disagree }-3= \\
\text { Somewhat Disagree }-4=\text { Somewhat Agree }-5=\text { Agree }-6=\text { Strongly } \\
\text { Agree }\end{array}$ & 1 & 2 & 3 & 4 & 5 & 6 \\
\hline $\begin{array}{l}\text { I feel confident in representing my work area in meetings with } \\
\text { management. }\end{array}$ & & & & & & \\
\hline $\begin{array}{l}\text { I feel confident contributing to discussions about the company's } \\
\text { strategy. }\end{array}$ & & & & & & \\
\hline I feel confident presenting information to a group of colleagues. & & & & & & \\
\hline $\begin{array}{l}\text { If I should find myself in a jam at work, I could think of many } \\
\text { ways to get out of it. }\end{array}$ & & & & & & \\
\hline Right now I see myself as being pretty successful at work. & & & & & & \\
\hline I can think of many ways to reach my current work goals. & & & & & & \\
\hline $\begin{array}{l}\text { At this time, I am meeting the work goals that I have set for } \\
\text { myself. }\end{array}$ & & & & & & \\
\hline I can be "on my own" so to speak at work if I have to. & & & & & & \\
\hline I usually take stressful things at work in stride. & & & & & & \\
\hline $\begin{array}{l}\text { I can get through difficult times at work because I've experienced } \\
\text { difficulty before. }\end{array}$ & & & & & & \\
\hline I always look on the bright side of things regarding my job. & & & & & & \\
\hline $\begin{array}{l}\text { I'm optimistic about what will happen to me in the future as it } \\
\text { pertains to work. }\end{array}$ & & & & & & \\
\hline
\end{tabular}




\section{Cyberloafing}

\begin{tabular}{|c|c|c|c|c|c|c|}
\hline \multicolumn{2}{|c|}{$\begin{array}{l}\text { CYBERLOAFING } \\
\text { Please indicate how often you engaged in activities listed below during } \\
\text { working hours ( } 1=\text { Never to } 5=\text { Constantly) }\end{array}$} & \multirow[t]{2}{*}{1} & \multirow[t]{2}{*}{2} & \multirow[t]{2}{*}{3} & \multirow[t]{2}{*}{4} & \multirow[t]{2}{*}{5} \\
\hline 1. & Browsing Sports related web sites & & & & & \\
\hline 2. & Browsing Investment related web sites & & & & & \\
\hline 3. & Browsing Entertainment related web sites & & & & & \\
\hline 4. & Browsing General news sites & & & & & \\
\hline 5. & Browsing Non-Job related web sites & & & & & \\
\hline 6. & Browsing Download non-work related information & & & & & \\
\hline 7. & Browsing Shop online for personal goods & & & & & \\
\hline 8. & Browsing Adult-oriented (Sexually Explicit) Web sites & & & & & \\
\hline 9. & Checking non-wok related e-mail & & & & & \\
\hline 10. & Sending non-work related e-mail & & & & & \\
\hline & Receiving non-work related e-mail & & & & & \\
\hline
\end{tabular}

Copyright: @ 2019 Agarwal. This is an open-access article distributed under the terms of the Creative Commons Attribution-NonCommercial 3.0 Australia License, which permits noncommercial use, distribution, and reproduction in any medium, provided the original author and AJIS are credited.

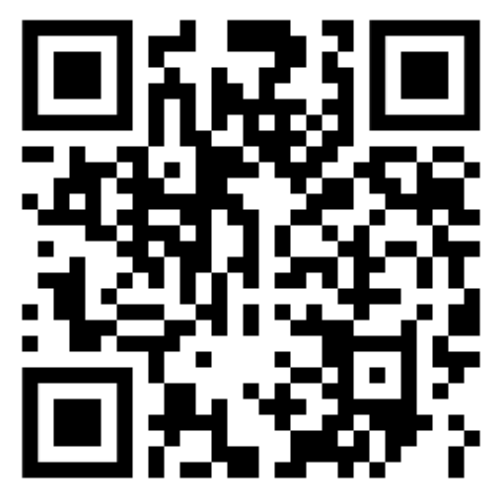

